\title{
Do aço aos carros: processos de industrialização e formação de classe no Sul Fluminense ${ }^{\mathrm{I}}$
}

\author{
Marcela Rabello de Castro Centelhas, Samantha de Andrade Gifalli \\ \& Thiago Brandão Peres*
}

Resumo: Pretendemos realizar uma abordagem comparativa entre duas experiências de industrialização, ocorridas na região Sul do estado do Rio de Janeiro. Nosso estudo examinou processos de formação da classe trabalhadora, tanto no caso da implantação da Companhia Siderúrgica Nacional (CSN), nos anos 1940-1950; quanto no da Volkswagen Ônibus e Caminhões (VW), nos anos 19902000. Analisaremos o conjunto de mecanismos e estratégias utilizados pelo Estado e pelas empresas para constituição de uma força de trabalho, as implicações destes nas condições de vida e de trabalho dos trabalhadores e em suas práticas organizativas e mobilizatórias. A atividade de pesquisa utiliza métodos quantitativos e qualitativos. Consultamos bibliografia especializada das Ciências Sociais, jornais e periódicos da rede mundial de computadores e da Biblioteca Nacional, bem como depoimentos de atores sociais. Também teremos como suporte os dados de perfil coletados em dois surveys (2001 e 2009) realizados pelo Núcleo de Estudos Trabalho e Sociedade (NETS/IFCS/UFRJ) com os trabalhadores da VW e das empresas participantes do consórcio modular.

Palavras-chave: trabalho, trabalhadores, sindicalismo, cultura de direitos, conflito.

\section{0 aço da CSN}

Sob o contexto do Estado Novo, situaram-se no Rio de Janeiro, na década de 1940, as iniciativas precursoras da atuação do Estado enquanto produtor direto. A

\footnotetext{
${ }^{\mathrm{I}} \mathrm{O}$ presente artigo é fruto de intenso trabalho coletivo junto ao Núcleo de Estudos Trabalho e Sociedade (NETS/ IFCS/UFRJ). Os autores agradecem aos integrantes do NETS pela oportunidade do trabalho conjunto e pela troca de conhecimento e experiência ao longo de todos os anos de estudos dedicados ao mundo do trabalho. Os resultados desta pesquisa foram apresentados em diversos eventos científicos, entre eles, o Primeiro Encontro ANPOCS de Iniciação Científica. Aproveitamos para agradecer a Ruy Braga (USP) e a Maria Aparecida Bridi (UFPR) pelas críticas e sugestões que foram essenciais para a elaboração deste artigo. Em especial, agradecemos ao nosso orientador, Prof. Dr. Marco Aurélio Santana, pessoa crucial para a construção desta pesquisa e, principalmente, para a nossa formação. Dedicamos este texto aos amigos Danilo de Castro Magalhães e Renata Barbosa Lacerda pelo apoio e pelas palavras de incentivo, ressaltando a importância do coletivo para a construção do conhecimento, para além do mérito individual.
}

* Graduandos em Ciências Sociais - UFRJ. 
Companhia Siderúrgica Nacional, ou CSN, criada em 1941, representou um estímulo à produção industrial fluminense convertendo o Vale do Paraíba em um importante pólo industrial. Tinha-se como objetivo reforçar a ação econômica estatal, criando uma infra-estrutura para a industrialização e intimamente associada ao progresso. Para isto, era indispensável a siderurgia - área estratégica tanto no setor industrial quanto no militar. Ao fim, um decreto-lei criou a Companhia Siderúrgica Nacional em Volta Redonda, Rio de Janeiro. Na época, "a comunidade contava cerca de 2.800 habitantes, a maioria dedicada a atividades agropastoris. Uma década depois, já transformada em 'Cidade do Aço', sua população ultrapassava 39.000 pessoas" (MoRel, 2001, p. 50).

Em pesquisa realizada em 1970, pela própria Companhia, observou-se que mais da metade dos entrevistados provinham de Minas Gerais e cerca de 30\% do Rio de Janeiro, em sua maioria oriundos de zonas rurais.

\footnotetext{
O caminhão chegava lotadinho de homem [...]. Ali descia um por um do caminhão e dava o nome. Tinha muitos que não sabiam o nome. Aí eles batizavam. Tinham muitos que não sabiam o endereço, não sabiam o nome do pai, não sabiam o nome da mãe. 0 agenciador é que dava um nome. (entrevista de um operário aposentado) (MoREL, 2001, p. 56)
}

Nesses termos, os processos de admissão constituíam os momentos iniciais de socialização do trabalhador: além de ganharem um uniforme, realizavam exames médicos, eram individualizados e classificados segundo aptidões, local de origem e instruções. Estes ritos de admissão objetivavam o enquadramento na empresa, a criação de um grupo unificado e, de certo modo, uma ruptura com a história pessoal anterior.

\section{A 'família siderúrgica'}

Encerrada a fase de construção e iniciada a produção de aço, em 1946, a CSN reduziu sua força de trabalho: de 11.719 trabalhadores empregados, o contingente reduz-se para 8.054 em 1947. Para assegurar a fixação da força de trabalho e a submissão à disciplina fabril, além de reforçar os laços corporativos dos trabalhadores com a empresa, a CSN lançou mão de formas de recrutamento e treinamento enquanto instrumentos para a formação e consolidação do que viria a ser denominado "família siderúrgica", expressão que alude a um espírito de colaboração que deveria existir entre todos, chefes, subordinados, dirigentes e trabalhadores. 
A partir da citação abaixo, podemos perceber como a CSN se defrontou com a necessidade de formar sua própria força de trabalho a partir de uma mão-de-obra de origem rural ou sem experiência no trabalho industrial.

Os homens que vieram construir Volta Redonda, espontaneamente ou recrutados em seus Estados, eram bisonhos, quase sempre mal tratados, completamente ignorantes do que seria uma usina siderúrgica. Vieram como teriam ido para um garimpo procurar trabalho, ganhando o que eles julgavam ser uma boa remuneração. Em geral só conheciam quatro ferramentas: a enxada, a foice, o martelo e o facão. Como produtores de energia, além deles, sabiam que existiam o boi, o cavalo e muares (MoREL, 2001, p. 47; grifos nossos).

Observando atentamente, a citação acima, escrita pelo General Macedo Morais e Silva, primeiro presidente da CSN, traduz a concepção de que o problema brasileiro estava em seu povo sem formação, o qual seria um entrave para a constituição de uma nação industrial e moderna. Segundo esta concepção, a CSN viria a cumprir, além de uma função propriamente econômica, uma missão civilizatória: através do trabalho e da educação seriam formados cidadãos brasileiros.

Com o intuito de formação desse "operário modelo", a empresa lançou mão de um conjunto de mecanismos, desde os mais repressivos (policiamento, prisão), que deflagravam uma real militarização das relações de trabalho (os postos-chave de mando eram ocupados por militares), até outros que tinham por foco a consolidação da "família siderúrgica". Ou seja, se por um lado a Lei de Segurança Nacional e todo o aparato de regras apontavam para um controle e repressão explícitos dos trabalhadores, por outro, a concessão de casas e outros benefícios, a implantação de uma escola profissional e a qualificação via SENAI (Serviço Nacional de Aprendizagem Industrial) foram fundamentais para a formação de um operário sob medida para suprir as necessidades da CSN, ao introduzir os alunos à hierarquia, à disciplina e ao ritmo de trabalho, ao mesmo tempo em que incutiam o "espírito" de colaboração entre os integrantes da "família siderúrgica".

No espaço interno da fábrica, instalaram-se regras, proibições e incitações, além de benefícios, prêmios, e incentivos, destinados a assegurar a cooperação e o bom comportamento do trabalhador. 0 empregado devia zelar pelo material que a Companhia lhe confiava; era proibido de organizar e orientar manifestações coletivas de apreço ou desapreço sobre a siderúrgica; o chefe devia ser obedecido dentro e fora do recinto de trabalho. 0 tempo também era rigidamente controlado: cartões de ponto e boletins apresentavam minuciosamente as atividades exercidas indivi- 
dualmente pelo operário. Além disso, em 1946, a Companhia cuidou de estabelecer as Caixas Receptoras de Sugestões. Pode-se apontar que esta medida foi a precursora dos métodos participativos contemporâneos, cujo objetivo era recolher trabalhos apresentados pelos empregados e que, por sua vez, pudessem ser úteis aos serviços ou interesses da CSN. Os trabalhos não poderiam ser anônimos e, se utilizados, prêmios em dinheiro e menção honrosa eram concedidas ao autor. Dessa forma, podemos afirmar que, tanto na esfera fabril quanto na extrafabril, o conjunto das medidas supracitadas visava aprimorar o trabalhador "de hoje e o do futuro".

A concessão de casas pela Companhia, também era um elemento fundamental para a consolidação da família siderúrgica, pois colocava o trabalhador e seus familiares sob total dependência da Companhia. Segundo Leite Lopes (1992), a imobilização da mão de obra pela moradia possibilitava a fixação da força de trabalho e o controle sobre todas as esferas da vida do trabalhador, pois, afinal, este ficava à disposição da empresa, mesmo nas horas de folga:

Qualquer hora que precisava, estava ativo no trabalho, compreende? Largava às 4, se precisasse, 8 horas da noite, vinha em casa, que me achava em casa, levava pro serviço [...]. (S.E. ex-operário, chegado em 1943, foi Encarregado no Setor de Laminação) (MoREL, 2001, p. 67).

Todavia, a necessidade desse conjunto de estratégias demonstra as dificuldades de se moldar os tais seres "bisonhos" à disciplina fabril, o que nos permite afirmar que a imagem da "família siderúrgica" não foi passivamente interiorizada pelos trabalhadores, e não impediu o surgimento de reivindicações ligadas a conflitos reais, surgidos no chão da fábrica, e que foram, paulatinamente, sendo canalizados para o sindicato - que surge em 1945. Apesar de o sindicato ter, inicialmente, atuado segundo características típicas da gestão corporativa do movimento dos trabalhadores, pode-se dizer que ele adquire, gradualmente, uma certa autonomia e vai ganhando reconhecimento dos trabalhadores enquanto um canal legitimo de encaminhamento das reivindicações (MoREL, 1989).

Ângela de Castro Gomes (2005) afirma, que o trabalhismo foi construído por mecanismos de Estado inseridos numa esfera simbólica. Combinava benesses materiais com o reconhecimento positivo de uma identidade trabalhadora. Tal fato geraria um compromisso ético dos trabalhadores com o desenvolvimento e a ordem nacional em reciprocidade ao reconhecimento outorgado pelo Estado. Assim, o Estado passaria a controlar os trabalhadores e os sindicatos por meio da dádiva 
da legislação trabalhista e da construção da uma cidadania regulada, convertendo reivindicações populares em doações e concessões outorgadas ao mesmo tempo em que atualizava um projeto de construção do cidadão-trabalhador. Este foi o norte do projeto político que orientou a criação da CSN e a forma de gestão da sua força de trabalho.

Entretanto, em oposição à noção de "dádiva” veiculada pela Companhia, os trabalhadores começaram a contrapor uma concepção de direitos que a CSN deveria respeitar - por exemplo, ao exigirem o cumprimento dos direitos trabalhistas ou ao intervirem nas regras de concessão da "girafa". Nesses termos, como aponta Santana (2006), o sindicalismo metalúrgico e o processo de industrialização de Volta Redonda serviram como marco do desenvolvimento da região Sul Fluminense. Contudo, o movimento de reestruturação e reespacialização da produção industrial brasileira nos anos 1990 começou a complexificar esse cenário regional.

\section{Os carros da Volks}

As mudanças ocorridas no mundo do trabalho mantém relação, dentre outros aspectos, com a globalização da economia, ambos elementos que uma determinada literatura nos anos 1990 convencionou chamar de "reestruturação produtiva". Como combinação de complexos processos dentre os quais a intensificação do movimento de mundialização de capitais, o acirramento da concorrência a nível global e as transformações tecnológicas surgidas no bojo de um processo de inovações técnico-científicas, deu-se o processo de reespacialização de cadeias produtivas para novos territórios.

A década de 1990 é marcada, no Brasil, pela intensificação de uma forma de capitalismo que se modifica para vencer as dificuldades encontradas pelos antigos modos de organização da produção e da economia. Percebemos alterações nas esferas produtivas, mas também mudanças de valores, mudanças nos padrões de consumo, mudanças culturais (c.f., por exemplo, HARVEY, 1992; SENNETT, 2008; HARDT; NEGRI, 2005). Sendo assim, analisaremos como se constituiu a força de trabalho de uma fábrica compreendida dentro do período de neoliberalização da política e da

\footnotetext{
1 "Girafa" era o nome dado à participação dos trabalhadores nos lucros da empresa.
} 
economia brasileiras, bem como, quais foram os efeitos desse novo contexto nacional e internacional nas práticas organizativas dos trabalhadores.

Neste contexto, o município de Resende, no Rio de Janeiro, é palco da instalação, em 1996, da montadora alemã Volkswagen Ônibus e Caminhões ou Volks. Se comparada às tradicionais indústrias daquela região, como a CSN, a forma de organização da produção da montadora apresenta algumas mudanças como o consórcio modular². Essa forma de organização da produção se caracteriza, entre outros fatores, pela produção enxuta, por número reduzido de trabalhadores e pela participação dos fornecedores dentro da mesma linha de produção.

Todavia, para captar o principal significado de Resende, devemos atentar ao fato de que, apesar de toda a propaganda pública enfatizavando a tecnologia e a novidade, estudos posteriores atestaram que o "desenvolvimento tecnológico na fábrica e as mudanças nas políticas de trabalho foram mínimas" (ABREU; BEYNON; RAMALHO, 2006, p. 80). A fábrica, para muitos autores, estava, na verdade, baseada "em um sistema de fluxo da produção bastante convencional, que não dá nenhum espaço para o envolvimento do trabalhador ou do sindicato na sua configuração ou funcionamento" (ABREU; BEYNon; RAMALHo, 2006, p. 80). Contudo, são notáveis os esforços das empresas para assegurar que a nova fábrica recrutasse trabalhadores qualificados, aptos a se entrosarem com os novos arranjos produtivos. Nesse sentido, a presença de uma unidade SENAI em Resende foi capital.

Como mencionamos anteriormente, os operários da CSN possuíam uma "qualificação formal". Contudo, percebemos a consolidação de um "modelo de competências" em detrimento da "qualificação formal". Na Volks, o novo perfil de trabalhadores, portanto, passaria pela valorização de atributos diferenciados — privilegiando aspectos subjetivos do trabalhador tais como:

polivalência, capacidade de decisão e de iniciativa, pela cooperação, pela autonomia, pela responsabilidade, pela criatividade e participação efetiva deste trabalhador no processo produtivo (RocHA, 2006. p. 141).

\footnotetext{
${ }^{2} \mathrm{Na}$ 'montagem modular' levada a cabo em Resende, a Volkswagen isenta-se do processo de montagem, ocupando-se das atividades de gerenciamento da qualidade, do design e do marketing, enquanto as demais empresas subcontratadas envolvem-se com o cotidiano da linha. Nessa inovadora forma de produção, divide-se entre as firmas participantes do consórcio a estrutura física e o financiamento da fábrica, constituindo uma forma de divisão dos riscos de investimento em espaços produtivos
} 
Além da preocupação com a qualificação, a Volkswagen também atentou para outros elementos da formação da classe trabalhadora, como os possíveis conflitos dentro de fábrica decorrentes da pluralidade de firmas e suas respectivas formas de lidar com a força de trabalho. Com o intento de atenuar essas disparidades, a empresa instituiu um uniforme único, utilizado até mesmo pelos executivos, assim como adotou uma política de salários e benefícios que fosse comum a todos os participantes do consórcio.

\section{Um perfil dos trabalhadores da Volks: trabalho e conflito}

Nos anos de 2001 e 2009, o Núcleo de Estudos Trabalho e Sociedade (NETS/ IFCS/UFRJ) ${ }^{3}$ realizou dois surveys com trezentos ${ }^{4}$ trabalhadores da Volks e das empresas participantes do consórcio modular. A continuação da série histórica - de 2001 a 2009 - permitiu que pudessem ser acompanhadas de perto as continuidades e transformações ocorridas tanto no perfil dos trabalhadores como na região Sul Fluminense. Através das questões aplicadas, foi possível captar aspectos tais como: perfil sócio-econômico, escolaridade e formação profissional, além da percepção dos trabalhadores acerca de seus organismos de representação.

Para a formação de classe, no caso da Volks, é necessário apontar a estratégia de alocar a montadora num greenfield. Tal mecanismo relaciona-se intimamente com a tentativa da montadora de prevenir e evitar a contratação de trabalhadores mais experientes, principalmente aqueles oriundos da CSN - de elevada tradição operária e sindical.

A partir dessa chave de análise, compreendemos a preferência da Volks em contratar uma mão de obra predominantemente local (Gráfico 1), evitando, assim, o recrutamento de trabalhadores naturais de Volta Redonda.

\footnotetext{
${ }^{3}$ O NETS é um núcleo de pesquisa da Universidade Federal do Rio de Janeiro, vinculado ao Programa de Pósgraduação em Sociologia e Antropologia (PPGSA) da mesma instituição.

${ }^{4}$ Em 2009 a amostra foi calculada com um intervalo de confiança de 95\% e margem de erro de 5 pontos percentuais. A população de trabalhadores na fábrica da Volkswagen em Resende é de 1767. 0 cálculo do tamanho da amostra ficou em 300 entrevistas.
} 


\section{Gráfico 1}

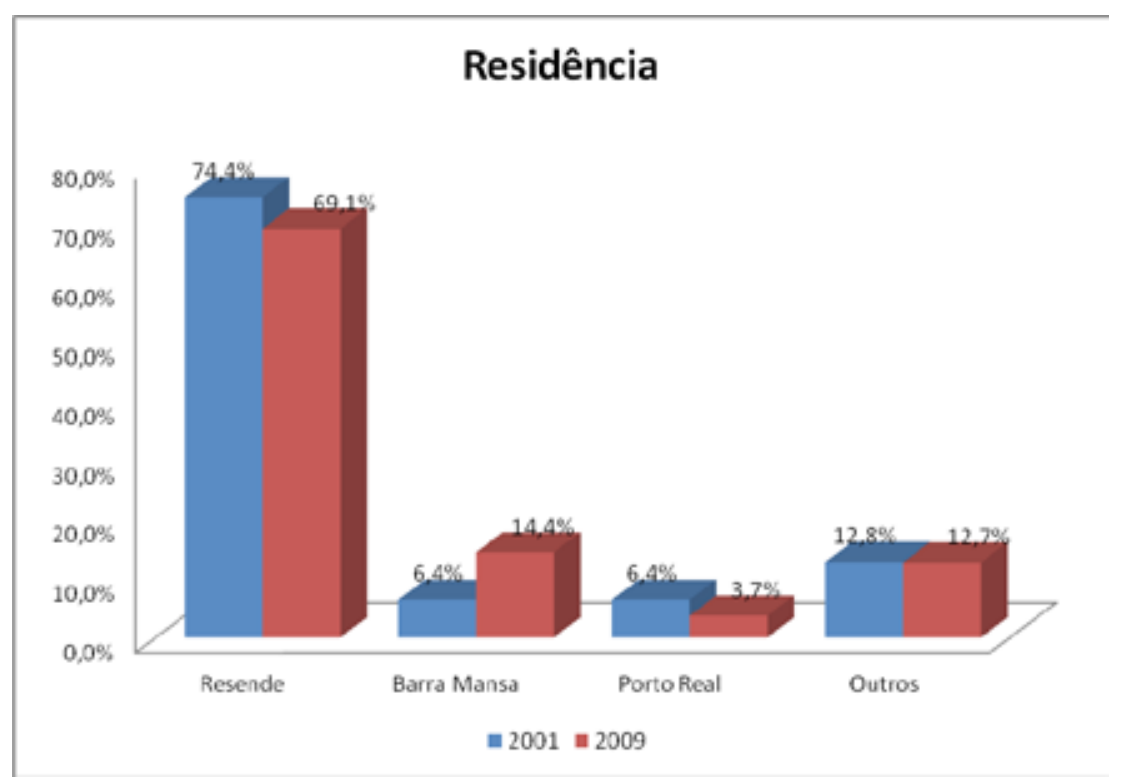

Fonte: Survey realizado pelo Núcleo de Estudos Trabalho e Sociedade (NETS/IFCS/UFRJ).

Da mesma forma, percebemos que, devido a um maior grau de escolaridade dentre a população brasileira mais jovem na atualidade, a estratégia de contratação de operários com segundo grau completo (Gráfico 3) está intimamente associada à outra estratégia: a de recrutamento de uma força de trabalho predominantemente jovem (Gráfico 2).

\section{Gráfico 2}

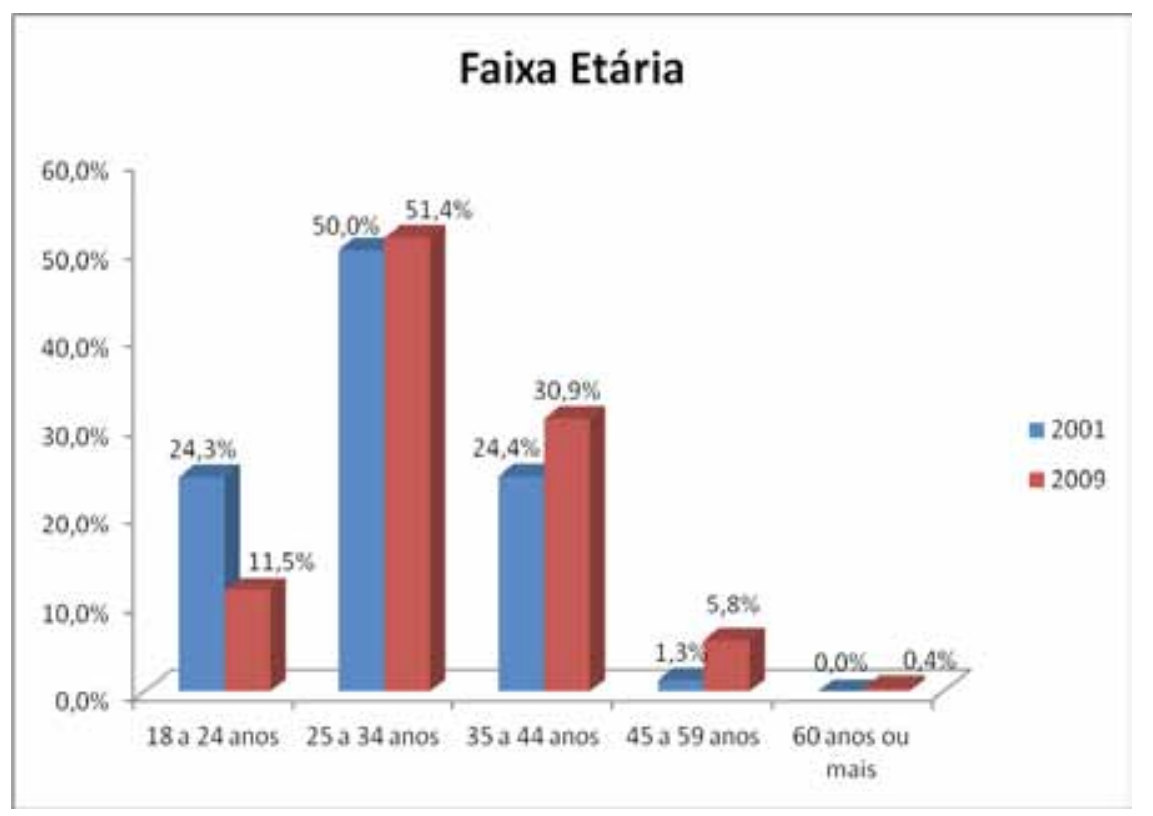

Fonte: Survey realizado pelo Núcleo de Estudos Trabalho e Sociedade (NETS/IFCS/UFRJ). 


\section{Gráfico 3}

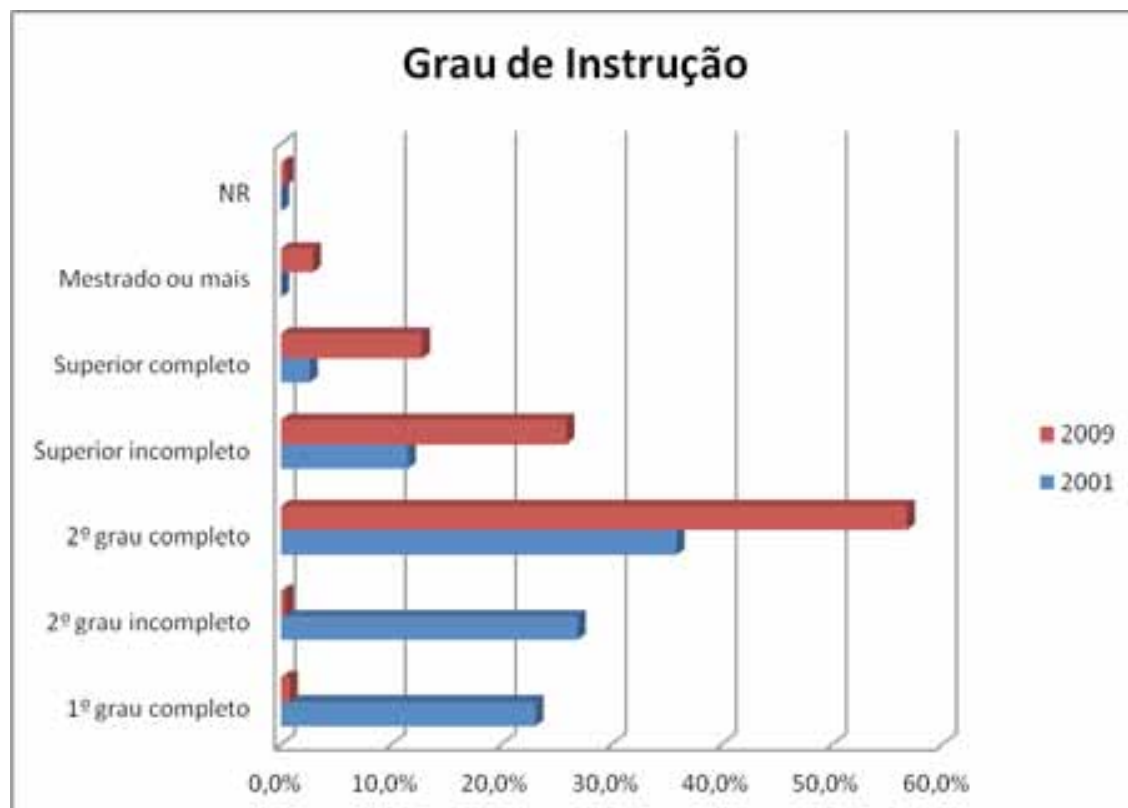

Fonte: Survey realizado pelo Núcleo de Estudos Trabalho e Sociedade (NETS/IFCS/UFRJ).

No entanto, foi possível perceber que essas estratégias não foram passivamente interiorizadas e os trabalhadores reagiram aos mecanismos de gestão de atenuação do conflito. A suposta 'docilidade' do sindicato local dos metalúrgicos, controlado pela Força Sindical - considerada mais afável do que a Central Única dos Trabalhadores (CUT) presente no ABC Paulista -, não se mostrou tão evidente.

Em 1999, apenas três anos após a instalação da montadora, deflagra-se uma greve entre os trabalhadores da Volks, não somente do Sul Fluminense, mas também em outras plantas da empresa pelo país. A pauta do movimento em Resende reivindicava, dentre outros, a paridade de salários com os metalúrgicos do $\mathrm{ABC}^{5}$, o fim do "banco de horas" ${ }^{6}$ e o estabelecimento de uma comissão de fábrica unificada7.

\footnotetext{
${ }^{5}$ A noção de paridade é muito poderosa e tem sido vista como crítica pelos trabalhadores da indústria automobilística por toda a Europa e Estados Unidos. Era uma clara preocupação do sindicato de Resende, e durante os anos 1990 se tornou também um assunto fundamental para os sindicatos do ABC. Para estas entidades, a dispersão das fábricas para fora do $\mathrm{ABC}$ foi encarada com uma estratégia de baixos salários por parte da indústria.

${ }^{6} \mathrm{O}$ 'banco de horas' opera com um entendimento de semana média de trabalho que a empresa pode reduzir ou aumentar conforme a demanda, sem qualquer penalidade para qualquer dos lados. Os trabalhadores não perderiam seus salários nas semanas mais curtas e a empresa não teria que pagar hora extra nas semanas mais longas.

${ }^{7}$ Inicialmente, seguindo a lógica do consórcio modular, a VW tinha se recusado formalmente a estabelecer canais de negociação coletiva, considerando que esses arranjos eram de responsabilidade individual dos membros do "consórcio". Contudo, isto provou ser problemático e, em 1999, após a greve, a Volks e as demais empresas concordaram em formalizar uma comissão de fábrica unificada.
} 
A greve de 1999 foi avaliada pelo sindicato enquanto vitoriosa ao conseguir que a comissão de fábrica unificada fosse aceita pela empresa e que a política do banco de horas fosse restringida e, posteriormente, extinta. No mesmo ano da greve, a notícia de formalização do Comitê Mundial dos Trabalhadores da Volks também parece muito relevante no que tange a reatualização das formas de enfrentamento da classe trabalhadora.

Tanto a greve de 1999, quanto a formalização do Comitê nos mostram que mesmo a combinação de uma força de trabalho majoritariamente local, jovem e com grau de escolaridade relativamente elevado, de baixa tradição industrial e sem experiência sindical não impediu o surgimento de conflitos reais e a sua paulatina canalização para o sindicato. Esse, por sua vez, a partir de experiências prévias decorrentes das mudanças industriais no ramo siderúrgico, não se mostrou passivo diante das estratégias da empresa.

Percebemos no gráfico 4 que, no ano de 2001, período de grande efervescência sindical pela vitória da greve de 1999 e pelo surgimento da comissão de fábrica, a percentagem de sindicalizados correspondia a 62,8\% dos trabalhadores. Contudo, em 2009, oito anos depois, esse quadro se altera. Podemos ver uma queda significativa no percentual de sindicalizados, que cai para $27,2 \%$.

\section{Gráfico 4}

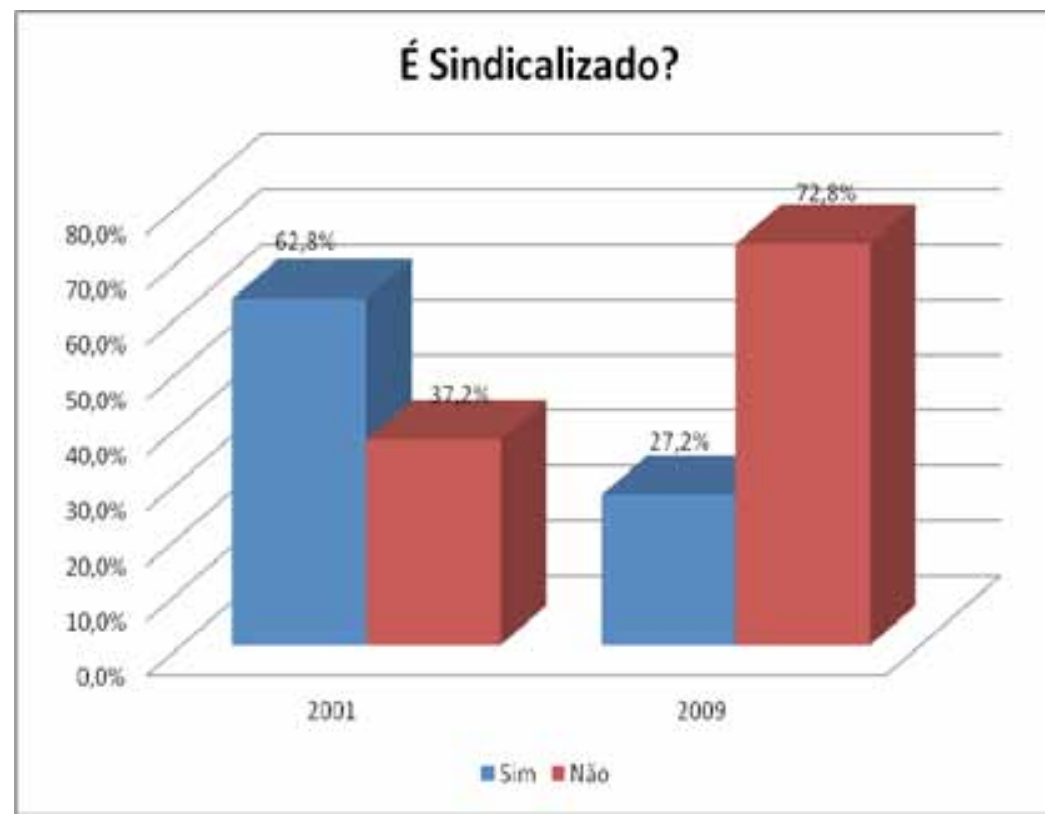

Fonte: Survey realizado pelo Núcleo de Estudos Trabalho e Sociedade (NETS/IFCS/UFRJ). 
No gráfico 5, em que é perguntado "Por que não é sindicalizado?", o alto índice conferido aos dois últimos itens - "Não tenho informações suficientes" e "Não acredito nos sindicatos" - pode manifestar que o progressivo afastamento das lideranças do chão-de-fábrica, a partir de 2002, pode ter contribuído para a queda na sindicalização.

\section{Gráfico 5}

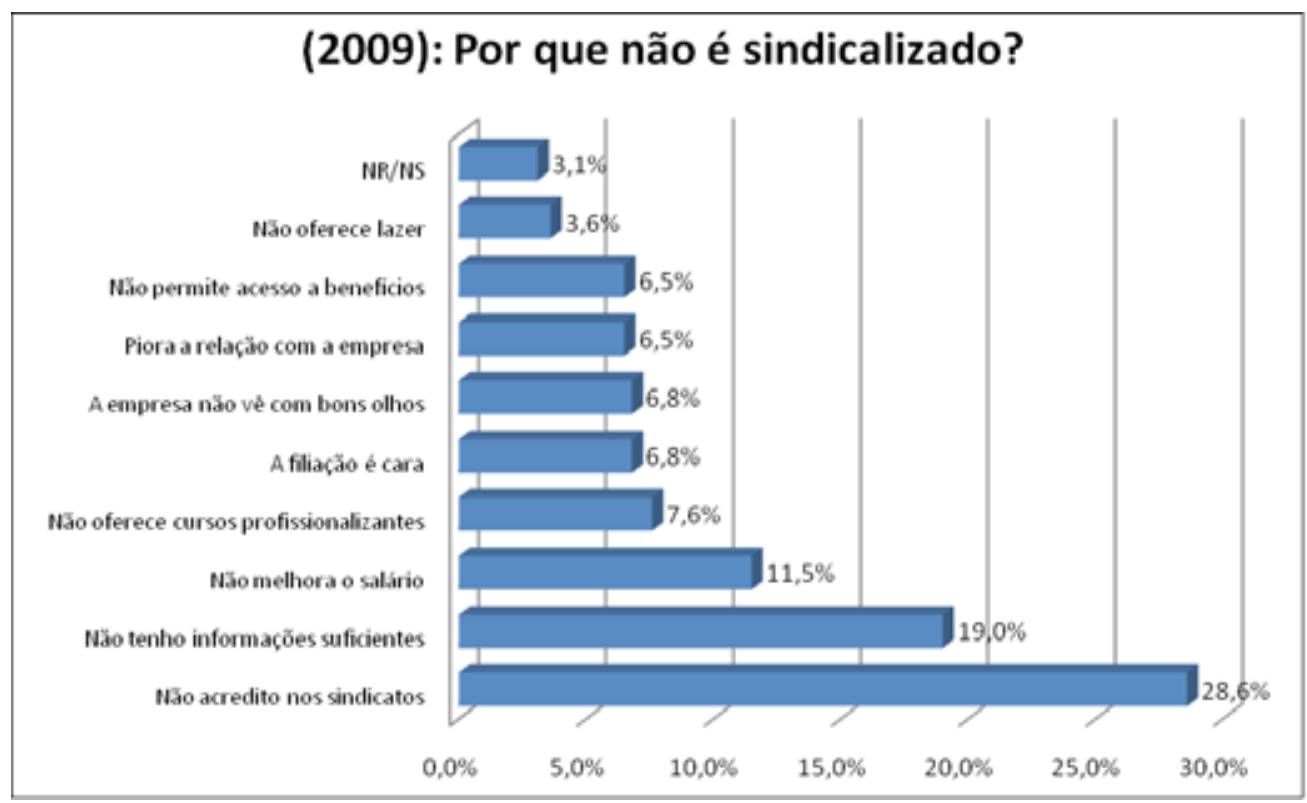

Fonte: Survey realizado pelo Núcleo de Estudos Trabalho e Sociedade (NETS/IFCS/UFRJ).

Parece claro que a escolha do Sul Fluminense para a instalação da fábrica corresponde a interesses da Volks de se distanciar dos "maus hábitos" de São Bernardo (ABReu; Beynon; RAmalho, 2006), optando por regiões onde seria supostamente mais 'fácil' negociar com o sindicato. Visava-se mesmo, como aponta Santana (2010), a criação de um "cordão sanitário", impedindo que o "veneno" sindical e conflitivo pudesse contaminar a "tenra" classe operária que se levantava do chão em tão pouco tempo.

Desse modo, percebemos que, assim como na CSN, as estratégias empresariais não foram passivamente interiorizadas e não impediram o surgimento de conflitos e reivindicações. Da mesma forma, mesmo que hoje o sindicato passe por uma crise que põe em cheque a sua capacidade de representação de uma classe trabalhadora, podemos dizer que ele permanece sendo um caminho legítimo de luta por direitos. 


\section{Do aço aos carros}

Nosso estudo buscou compreender a formação e consolidação da classe trabalhadora, bem como as suas formas organizativas e mobilizatórias em dois períodos claramente demarcados (décadas de 1940-1950 e 1990-2000) que tiveram lugar no Sul Fluminense. A CSN marcou, em muito, os traços industriais de toda a região. Hoje, apesar da continuada importância desta empresa, a chegada da indústria automobilística, concreta e simbolicamente, deu novos ares às características industriais locais.

De um lado, uma classe operária formada sob a interpelação referente à "família siderúrgica" e nascida sob a égide do "trabalhismo" e do progresso da nação. De outro, uma classe trabalhadora que valoriza a necessidade dos estudos e que reproduz o discurso do progresso por meio do aperfeiçoamento individual.

No entanto essa concepção de "família siderúrgica" na CSN não foi passivamente interiorizada, e não impediu o surgimento de reivindicações e expectativa de direitos, assim como na Volks, a combinação entre uma classe operária mais jovem, local, mais escolarizada em um território com pouca tradição sindical criou, sim, dificuldades para as lideranças sindicais mais tradicionais. Entretanto, paralisações, mobilizações e greves buscando a paridade de salários com os metalúrgicos do $\mathrm{ABC}$, o fim do "banco de horas" e a consolidação de uma comissão de fábrica unificada nos revelam também uma capacidade de reatualização das formas de organização por parte do Sindicato dos Metalúrgicos ao abordar as profundas transformações por que passou a localidade nas últimas décadas.

\section{Referências}

Abreu, A. P.; Beynon, H.; Ramalho, J. R. (2006). "A fábrica dos sonhos da Volkswagen”. In: RAmalho, J. R.; SAntana, M. A. (Org.). Trabalho e desenvolvimento regional - efeitos sociais da indústria automobilística no Rio de Janeiro. Rio de Janeiro, Mauad, p. 71-90.

Beynon, H. (2003). “O sindicalismo tem futuro no século XXI?”. In: Ramalho, J. R.; Santana, M. A. (Org.). Além da fábrica. São Paulo, Boitempo, p. 44-71.

Cardoso, A. M. (2003). "Os sindicatos e a segurança socioeconômica no Brasil". In: Ramalho, J. R.; Santana, M. A. (Org.). Além da fábrica. São Paulo, Boitempo, p. 227270.

CAStel, R. (1998). As metamorfoses da questão social. Petrópolis, Vozes. 
Gomes, A. C. (2005). A invenção do trabalhismo. Rio de Janeiro, Ed. FGV.

HARDT, M.; NeGRI, A. (2005). Império. São Paulo, Record.

HaRvey, D. (1992). A condição pós-moderna. São Paulo, Edições Loyola.

Lopes, J. S. L. (1978). Vapor do diabo: o trabalho dos operários do açúcar. Rio de Janeiro, Paz e Terra.

Morel, R. L. M. (2001). “A construção da 'família siderúrgica' - gestão paternalista e empresa estatal”. In: RAMALHo, J. R.; SANTANA, M. A. (Org.). Trabalho e tradição sindical no Rio de Janeiro: a trajetória dos metalúrgicos. Rio de Janeiro, D. P\&A, p. 45-78.

Ramalho, J. R. (2000). “Trabalho e Sindicato: posições em debate na sociologia hoje”. Dados, vol. 43, n. 4.

RochA, L. M. (2006). "O novo discurso da qualificação profissional da indústria automobilística do Rio de Janeiro". In: Ramalho, J. R.; Santana, M. A. (Org.). Trabalho e desenvolvimento regional - efeitos sociais da indústria automobilística no Rio de Janeiro. Rio de Janeiro, Mauad, p. 137-158.

Santana, M. A. (2006). "Trabalhadores e política no Sul fluminense: a experiência de Volta Redonda nos anos 1980". In: Ramalho, J. R.; Santana, M. A. (Org.). Trabalho e desenvolvimento regional - efeitos sociais da indústria automobilística no Rio de Janeiro. Rio de Janeiro, Mauad.

(2010). "Ruptura geracional induzida e estratégias de gestão: a experiência nas montadoras do Sul Fluminense". Educação e sociedade, Campinas, vol. 31, n. 111, p. 371-389.

Santos, W. G. (1979). Cidadania e justiça. Rio de Janeiro, Campus.

Sennett, R. (2008). A corrosão do caráter. Rio de Janeiro, Record.

WefFort, F. (1986). O populismo na política brasileira. Rio de Janeiro, Paz e Terra.

Recebido em dezembro/2012

Aprovado em janeiro/2013 